\title{
TIMING OF PRE-NUPTIAL MIGRATION OF THE SONG THRUSH TURDUS PHILOMELOS IN CALABRIA (SOUTHERN ITALY)
}

\author{
Eugenio Muscianese', Giuseppe Martino², Pasquale Sgro ${ }^{3}$, \\ Sergio Scebba ${ }^{*}$ and Michele Sorrenti ${ }^{5}$
}

\begin{abstract}
Muscianese E., Martino G., Sgro P., Scebba S. and Sorrenti M. 2018. Timing of pre-nuptial migration of the Song Thrush Turdus philomelos in Calabria (southern Italy). Ring 40: 19-30.

The European Commission has established that pre-nuptial migration of the Song Thrush Turdus philomelos in Italy begins in the second decade (10-day period) of January. This three-year study was carried out at two localities in the Calabria region of southern Italy from 2012 to 2014, with 3-4 ringing sessions every decade from mid-January to the end of March. In total, 447 birds were captured. Based on catching dynamics and changes in fat load and body mass, we documented that the species' northward migration took place in mainly March, with early movements in February. As no migratory activity was detected before the second decade of February, the dates of the hunting season in this area can be re-considered.

${ }^{1}$ E. Muscianese, Via De Risio 62, I-88832 Santa Severina (Crotone), Italy;

${ }^{2}$ G. Martino, Via del Tordo 20, I-89131 Reggio Calabria, Italy;

${ }^{3}$ P. Sgro, Via Peripoli 197, I-89030 Condofuri (Reggio Calabria), Italy;

${ }^{4}$ S. Scebba (corresponding author), Traversa Napoli 58, 80078 Pozzuoli (Napoli), Italy, e-mail: serscebba@katamail.com;

${ }^{5}$ M Sorrenti, FIDC - Ufficio Avifauna Migratoria, Via Salaria 298/a, I-00199 Rome, Italy
\end{abstract}

Keywords: Song Thrush, southern Italy, spring migration, timing, Turdus philomelos

\section{INTRODUCTION}

In Italy, the Song Thrush is a common species during both migrations and wintering, with populations coming from a wide geographical area extending from centraleastern France to central Russia, as well as from the northern Baltic coasts and Finland to the Balkans, and to the east to beyond the Urals, as confirmed by analysis of ringing and recovery data (Andreotti et al. 1999, Spina and Volponi 2008), mostly concentrated in the north and centre of the peninsula (Andreotti et al. 2010). Birds wintering in Mediterranean countries arrive in October, but continue to arrive 
throughout the autumn. Winter movements, probably related to climatic conditions and food search, are common in southern Europe and the Middle East (Andreotti et al. 2010).

In regions of southern Italy, due to low ringing effort, knowledge of various migrating populations, the main flyways and the timing of northward migration is quite scarce (Andreotti et al. 1999). Furthermore, these regions are probably reached by birds coming from areas where ringing at nests is not practiced, especially from central and northern European Russia, Belarus, Ukraine and the Balkans, and from Eastern Europe in general (Spina and Volponi 2008, La Gioia and Scebba 2009). This shortage of data is particularly pronounced in the Calabria region (southern Italy), where the Song Thrush is considered a regular migratory and wintering species (Scebba et al. 1993). No studies have been conducted to properly evaluate its phenology.

Article 7 (4) of Council Directive 147/2009CE (ex 79/409/EEC) on the conservation of wild birds (known as the Birds Directive) provides a common framework for the conservation of naturally occurring species of wild birds and their habitats throughout the European Union and lays down key principles relating to the establishment of hunting seasons. The objective is to prevent hunting from taking place during the most vulnerable periods of the annual cycle of huntable species. In the case of migratory species, Member States are to ensure that species to which hunting regulations apply are not hunted during their return to their rearing grounds. The EU Court of Justice has stated that the article seeks to ensure complete protection of those species during the pre-nuptial migration period. In the analysis report Key concepts document on period of reproduction and prenuptial migration of huntable bird species in the $E U$, available on the European Union website (http://ec.europa.eu/environment/nature/conservation/ wildbirds/hunting/key_concepts_en.htm), the data are presented in decades (10-day periods). According to the Guide to Sustainable Hunting under the Birds Directive, paragraph 2.7.2, 'an overlap of one decade between hunting date and the period of prenuptial migration or reproduction is categorised as a theoretical overlap as during this period it is possible that there may not actually be an overlap. For periods of greater than 1 decade of overlap there is no such uncertainty as this is therefore a real overlap'.

The European Commission, on the basis of the information provided by the Italian Institute for Environmental Protection and Research (ISPRA) (Spina and Serra 2003, Andreotti et al. 2004, Spina and Volponi 2008), determined that pre-nuptial migration of the Song Thrush Turdus philomelos in Italy begins in the second decade of January. As a result, the closing date for the hunting of Song Thrush was set as 20 January, which was earlier than the date of January 31 established by Law No. 157 of 11 February 1992 regulating hunting in Italy. This situation has created considerable difficulties in drawing up regional hunting regulations, and some regions have conducted studies in order to update the Key concepts document. It should be noted that the start of pre-nuptial migration in Italy in the second decade of January is the earliest among countries of the European Community where the species is huntable, e.g. Spain (first decade of February), France (second decade of February), Portugal and Greece (third decade of February) or Malta (third decade of January), the last of which is located south of Italy. Furthermore, the closing date is established at a national level and does 
not take into account any regional differences that may exist in the pre-nuptial migration period within a Member State. This possibility is considered in the Guide, paragraphs 2.7.3 and 2.7.10. However, it should be specified that Article 10 requires Member States to encourage research and 'any work required as a basis for the protection, management and use of the population of all species of birds referred to in Article $I^{\prime}$ and the case-law of the Court of Justice underscores the importance of using the best available scientific information as a basis for implementing the Directive.

A few studies carried out in three regions of central and southern Italy, i.e. the province of Latina in Lazio (Scebba et al. 2014), the province of Lecce in Puglia (Scebba et al. 2015) and the province of Salerno in Campania (Scebba and Oliveri Del Castillo 2017), have attempted to identify the decade in which northward migration begins. The present three-year study was carried out at two locations in the Calabria region to complement the previous research.

\section{METHODS}

\section{Study area and field protocols}

The fieldwork was carried out at two locations in Calabria (southern Italy), approximately $164 \mathrm{~km}$ apart, surrounding the township of Santa Severina (39 $10^{\prime} \mathrm{N} 16^{\circ} 55^{\prime} \mathrm{E}$ )

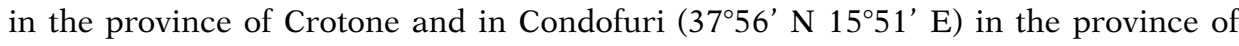
Reggio Calabria (Fig. 1), below $100 \mathrm{~m}$ a.s.l. In the province of Crotone the research was conducted on partially uncultivated farmland with olive groves bordering areas with citrus orchards, vineyards, extensive crops and reforestation with Eucalyptus sp. and Cupressus sempervirens. The study area also included small patches of Mediterranean riparian forest and pine woods with Pinus halepensis and Mediterranean maquis. In the province of Reggio Calabria, the area is partly occupied by olive groves, citrus orchards and extensive crops, and partly reforested with pine woods (with a greater presence of Aleppo pine and Mediterranean cypress) and Eucalyptus sp. The undergrowth is represented by Cistus monspeliensis, Euphorbia dendroides, Pyrus pyraster and Ampelodesmos mauritanicus.

The study was conducted from the second decade of January to the third decade of March in order to cover the period of pre-nuptial migration, at three ringing sessions in the province of Reggio Calabria and four in the province of Crotone for each decade. Approximately $400 \mathrm{~m}$ of nylon mist nets in the first location and $100 \mathrm{~m}$ in the second (2.40 m high, mesh size $28 \mathrm{~mm}$, four shelves) were placed inside the olive groves and on the margins between the latter and the reforestation areas, with a fixed orientation. Mist netting was carried out at least one hour before sunrise and netting continued for the next six hours without the use of sound lures; nets were checked every hour and birds captured were released immediately after ringing and measurements were completed.

Once captured, each bird was ringed with individual alloy rings on the tarsus and its age was determined according to the moult limit between moulted greater coverts (with rounded pale spots on the tips) and juvenile retained coverts (usually with trian- 
gular spots on the tips) (Svensson, 1992). Standard biometrics were collected, including wing length to the nearest $0.5 \mathrm{~mm}$ (flattened and straightened maximum wing chord according to Svensson (1992), using a stopped ruler), third primary length (flattened and straightened: Berthold and Friedrich 1979) to $0.5 \mathrm{~mm}$, and tarsus length (Svensson 1992) using a callipers $(0.1 \mathrm{~mm})$. The fat score was estimated and expressed as a number from 0 (no fat visible) to 8 (breast muscle completely covered with fat) (Kaiser 1993). Body mass was measured using a digital balance (Kern EMB 1200-1) to the nearest $0.1 \mathrm{~g}$.

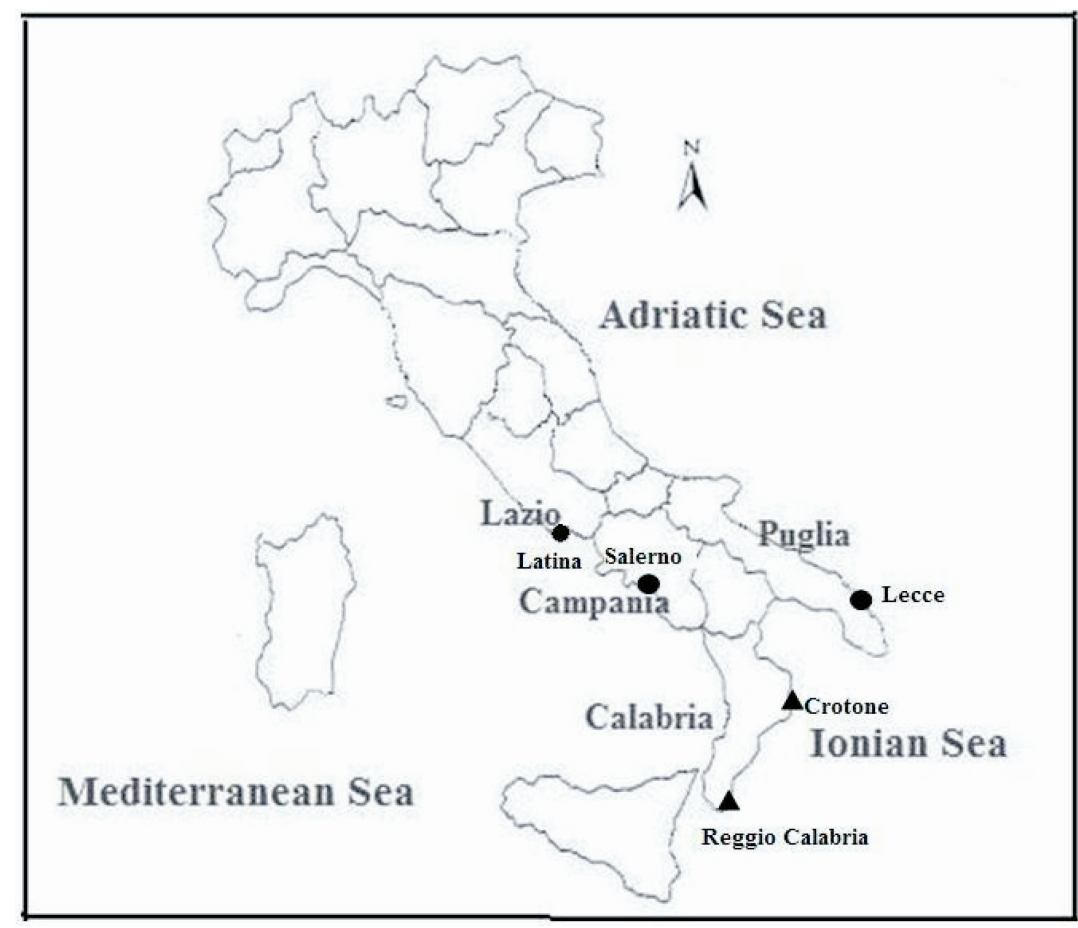

Fig 1. Map showing the locations of trapping sites in southern Italy: triangles - sites included in this study; circles - sites of previous research in the regions of Lazio, Puglia and Campania.

The data from all years were combined for the analysis and fitted into standard decades; the calendar year was divided into 36 decades of 10-11 days each, depending on the month (8-9 days in the case of the third decade of February) (Licheri and Spina 2002). The following statistics were calculated: mean and SD (standard deviation) of the measurement of wing length, third primary length and tarsus length for all ringed birds; means of body mass calculated for decades; and fat, expressed as the percentage of birds with a fat score equal to at least 3 . We used this score because individuals with scores 0-2 were considered totally or nearly free of visible fat deposits. 


\section{RESULTS}

A total of 175 capture sessions were conducted (99 in the province of Crotone and 76 in the province of Reggio Calabria); in total, 297 Song Thrushes were captured near Crotone, including 125 in 2012, 50 in 2013 and 122 in 2014, and 150 were captured in Reggio Calabria: 55 in 2012, 51 in 2013 and 44 in 2014.

The numbers of birds ringed during the three years of activity in both locations taken together (Table 1) showed an increasing trend up to the second decade of February, followed by a noticeable increase in the next three decades and a sharp decline in the last decade of March. A similar trend was observed even when the three years were considered separately.

Table 1

Numbers of Song Thrushes ringed in the townships of Santa Severina (Crotone) and Condofuri (Reggio Calabria) in successive decades of January-March 2012-2014

\begin{tabular}{|l|r|r|r|r|r|r|r|r|}
\hline & \multicolumn{2}{|c|}{ January } & \multicolumn{3}{|c|}{ February } & \multicolumn{3}{c|}{ March } \\
\cline { 2 - 9 } & II & III & I & II & III & I & II & III \\
\hline 2012 & 9 & 10 & 17 & 6 & 23 & 60 & 53 & 2 \\
\hline 2013 & 8 & 7 & 2 & 6 & 19 & 33 & 18 & 8 \\
\hline 2014 & 21 & 21 & 12 & 26 & 15 & 27 & 43 & 1 \\
\hline All years & 38 & 38 & 31 & 38 & 57 & 120 & 114 & 11 \\
\hline
\end{tabular}

As the monitoring during 2012-2014 was based on continuous mist netting involving the same catching locations and timing of mist netting, it is possible to estimate the trapping patterns during the study period by calculating the catching-effort index $(C I)$ for these three years. The patterns for both localities are similar within the locality (Fig. 2), although catching effectiveness was very different in these ringing sites. The general patterns (results from all years combined for the site - Fig. 3) are differentiated, but with a common attribute - a marked increase in numbers in the third decade of February. During the last two decades of January, the catching index calculated for the province of Crotone showed a very slight decrease in 2012 and 2013 and only a modest increase in 2014, while for the province of Reggio Calabria there was a declining trend from the beginning of mist netting to the first or second decade of February; for both locations the $C I$ showed some variation in year-to-year values but without peaks due to the arrival of migrants. The average $C I$ values during the last two decades of January were 0.89 for Crotone and 0.50 for Reggio Calabria, and the captures during that time account for only $11.8 \%$ and $27.3 \%$, respectively, of the total samples. A gradual but steady increase was always recorded from the third decade of February. The average catching index until the second decade of March (21 February-20 March) was 3.37 for Crotone and 0.44 for Reggio Calabria; the number of thrushes ringed represented $72 \%$ and $54 \%$, respectively, of the total samples. For the province of Crotone, the highest values were reached in the first decade of March, with an average capture level of 4.72 , and for Reggio Calabria in the third decade of 
February, with an average capture level of 0.50. In the third decade of March, a sharp decrease in the catching index was observed at both ringing stations.
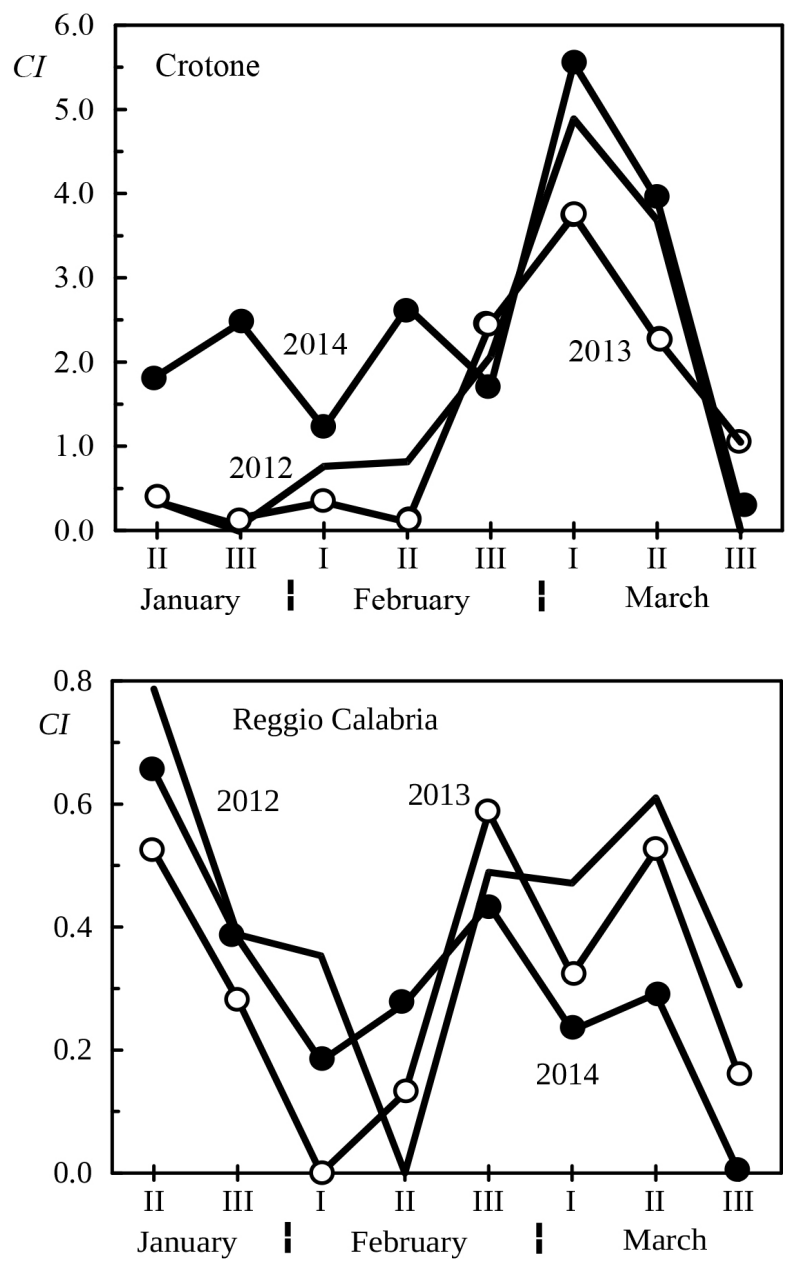

Fig 2. Catching index (CI) for decades of January-March in the years 2012-2014: upper panel Crotone, lower panel - Reggio Calabria.

Figure 4 shows the average changes in body mass over time. All data collected in the three years of the study and at the two catching locations are included. The average weight of the thrushes in the province of Crotone markedly increased between the third decade of February and the first decade of March, with the peak in the third decade of March. The province of Reggio Calabria showed the same increase in roughly the same time. Mean body mass calculated by decade showed the lowest values in the second decade of January and in the second decade of February for Crotone, while in Reggio Calabria the lowest values were recorded in the first and third decades of February. Significant increases were recorded from the third decade of 

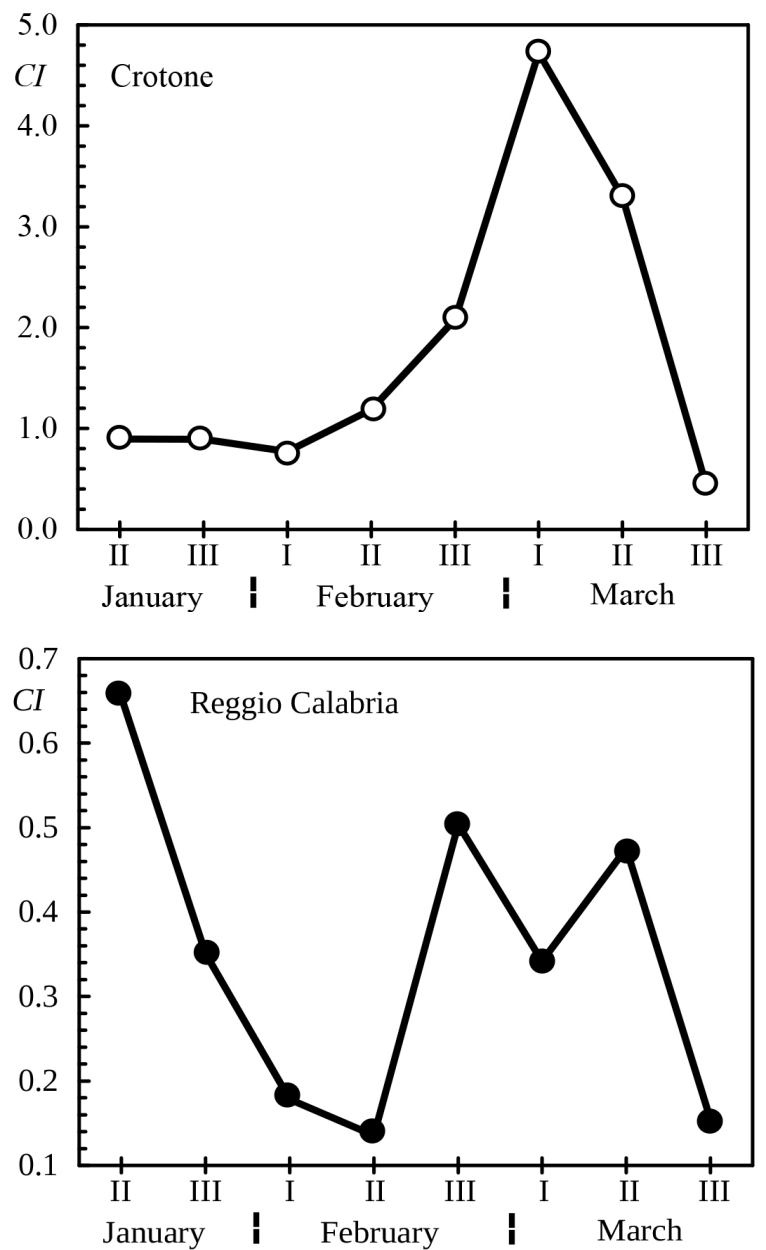

Fig 3. Total catching index $(C I)$ for decades of January at sites: upper panel - Crotone, lower panel - Reggio Calabria.

February for Crotone and from the first decade of March for Reggio Calabria, with the highest values detected in the last two decades of March.

A similar trend can be observed studying deposits of subcutaneous fat in thrushes, as shown in Figure 5, which presents the percentage of individuals with a fat score of 3 or higher. The graph shows that from the second decade of January until the second decade of February for Crotone and until the third for Reggio Calabria there were no captures of thrushes with high levels of fat deposits: $96.4 \%$ and $97.6 \%$ of all examined birds, respectively, were in class 0 or 1 . A significant presence of fat birds was detected only from the first decade of March for both sites, with a constant increase in the following decades. The thrushes with larger fat deposits (classes 3, 4 and 5) represented $29.9 \%$ of the individuals examined in the province of Crotone ( 89 birds of 298) and $17.1 \%$ of those examined in the Reggio Calabria area (26 birds of 152). A $74.4 \%$ 


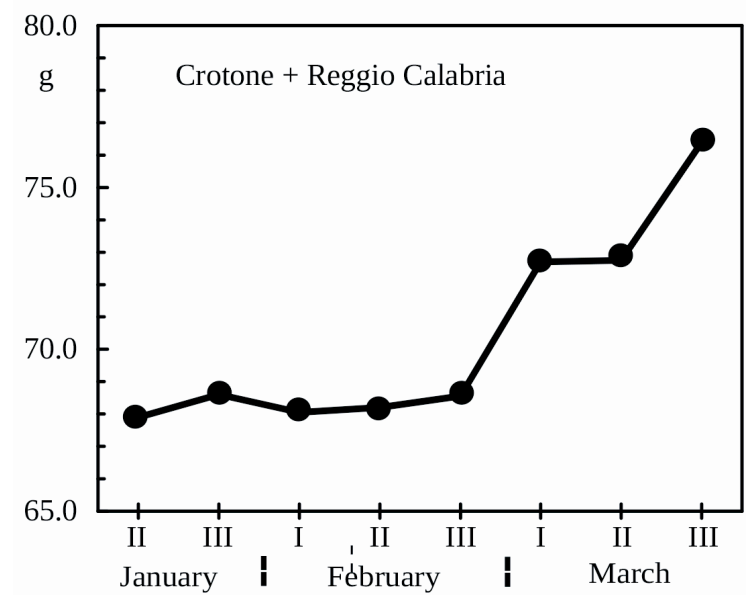

Fig. 4. Average body mass of thrushes caught in each decade of January-March. Combined data from 2012-2014 and both sites.

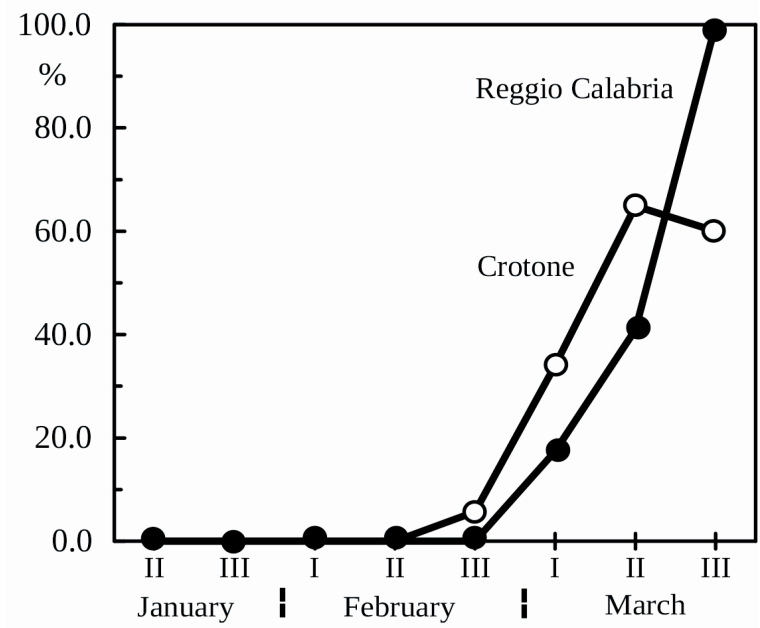

Fig. 5. Percentage of fatty birds (with a visible fat score of at least 3 ) in each decade of January-March. Combined data from 2012-2014.

share (335 birds) of the entire sample $(N=450)$ showed reduced or no fat reserves (0-2 classes). Maximum levels of fat (4-5) were recorded between the second and third decades of March, in both provinces. The growing share of fatty birds in the population supports earlier conclusions that pronounced migration begins during the first decade of March.

Of the 447 thrushes ringed over three years, two birds were controlled after 2 and after 7 days and four others after a period of 13 to 48 days. Body mass examination of these individuals showed decreases of $0.9,1.5$ and $2.7 \mathrm{~g}$ for three birds recovered at 
the end of February, while two individuals controlled in March showed weight increases of 0.1 and $1.4 \mathrm{~g}$ and another a decrease of $1.3 \mathrm{~g}$.

Mean wing length, third primary lengths and tarsus lengths calculated at the two locations for separate years and for all years combined are presented in Table 2. The values obtained for these morphometric variables did not differ from year to year (all pairwise $t$-tests show $\mathrm{p}>0.05$ ).

Table 2

Measurements (in $\mathrm{mm}$ ) of Song Thrushes ringed in Reggio Calabria and Crotone during the period from 11 January to 31 March, 2012-2014.

Averages and $S D$ are given, and sample size in brackets.

\begin{tabular}{|c|c|c|c|}
\hline & Wing & Third primary & Tarsus \\
\hline \multirow{2}{*}{2012} & $119.8 \pm 2.35$ & $89.5 \pm 1.98$ & $32.2 \pm 0.96$ \\
& $(181)$ & $(181)$ & $(178)$ \\
\hline \multirow{2}{*}{2013} & $119.5 \pm 2.77$ & $89.2 \pm 2.38$ & $32.3 \pm 1.03$ \\
& $(101)$ & $(101)$ & $(100)$ \\
\hline \multirow{2}{*}{2014} & $119.6 \pm 2.75$ & $89.2 \pm 2.20$ & $32.1 \pm 0.94$ \\
& $(165)$ & $(164)$ & $(164)$ \\
\hline \multirow{2}{*}{ Total } & $119.7 \pm 2.60$ & $89.3 \pm 2.16$ & $32.2 \pm 0.97$ \\
& $(447)$ & $(446)$ & $(442)$ \\
\hline
\end{tabular}

\section{DISCUSSION}

At both capture sites the presence of olive groves and plants with edible berries created a favourable habitat for the stopover and wintering of thrushes. Based on the observations, in the early hours of the morning, the thrushes move from wooded areas used as night-time shelters to pasture areas, and then return in the late afternoon. They also move between various cultivated areas during the day to search for new food sources. These movements seem to decrease roughly from the second or third decade of February, when the birds begin to show an increase in weight and deposits of subcutaneous fat.

As in any monitoring that involves handling of birds, individuals that have been captured tend to avoid the nets after a few days. Capture rates of resident individuals typically decline rapidly after the first day and after 3 to 5 days are extremely low, and thus a stable wintering population yields lower and lower catches. During periods with considerable day-to-day turnover in individuals (e.g. migration periods), capture rates are higher and the numbers caught markedly increase as waves of migrants pass through an area (Karr 1979, 1981). Accordingly, at least until the second decade of February, the number of thrushes ringed was fairly low (stable population), without peaks due to the arrival of migrant birds. The peak of captures for both provinces occurred on average between the third decade of February and the second decade of March. In the following decade, the areas were suddenly abandoned by almost all birds, and at the same sites in April only isolated individuals were observed. 
The species shows fidelity to its wintering grounds, as confirmed by some recoveries one year after ringing in the two research locations: five birds were controlled one year after the first ringing. Such fidelity, however, is not associated with a single location, but with a wider area within which wintering individuals make regular movements, depending on weather conditions and food availability.

This is also reported in the Key Concepts document (mentioned in the Introduction), which claims that the fact that birds leave a wintering area does not necessarily mean that they are beginning their return migration. They may be moving to other wintering quarters due to changes in local ecological conditions, disturbances, changes in climatic conditions, or depletion of food resources. The decrease of more than $40 \%$ in the number of catches in the province of Crotone in 2013 during this study was probably due to management of olive trees, especially pruning, which reduced food resources. Andreotti et al. (2010) have also reported that winter movements, probably related to climatic conditions and food search, are common in southern Europe and the Middle East.

The main element of migratory disposition is the accumulation of large fat reserves, which is more pronounced in typical migratory birds (Blem 1990, Bairlein and Gwinner 1994). Genetic factors, lengthening of the photoperiod and the consequent rise in temperature allow the birds to accumulate the energy reserves required for migration. Fat reserves are deposited by migrants according to the distance to be covered, the migratory period and their ecological condition (Berthold 2000).

During this research, the average body mass for both locations showed significant increases from the third decade of February, with the highest values recorded in March. The same trend was found in the accumulation of subcutaneous fat: until the second or third decade of February there were no captures of birds with high levels of fat deposits. The presence of individuals with low weights and reduced fat levels in this period, as well as the low number of ringed birds, indicates that the study area at that time is used only by wintering individuals. Moreover, several individuals recaptured at the same site one or two months after ringing did not show significant variations in fat levels, confirming that they were not yet ready to migrate. In subsequent decades, birds with fat level 3 were captured; these were nearly ready to leave the wintering area or had already begun their migration. Birds with fat scores of 4 and 5 , whose physiological condition was sufficient for return migration to the breeding areas, were ringed only in the first decade of March. This trend is very similar to that detected in similar studies carried out in other regions of central and southern Italy, i.e. in Lazio (Scebba et al. 2014), Puglia (Scebba et al. 2015) and Campania (Scebba and Oliveri Del Castillo 2017). According to these studies, the northward migration of the Song Thrush does not start before the end of the third decade of January, and increases significantly from the second to third decade of February, as has been found in southern France and in Corsica (Roux and Boutin 2003), a region geographically close to Italy and fairly morphologically equivalent to Sardinia.

Macchio et al. (1999), based on trapping activity in Italy in the years 1980-1994, have also stated that spring migration took place from February, as suggested by the trend in the annual index of abundance, calculated in order to correlate the number of captures with the ringing effort. Licheri and Spina (2002) also reported that ring- 
ing data collected in Italy in the years 1982-1999 showed that return migration lasted from February to April, with some individuals still present in early May.

The biometric measurements collected in the study area suggest that the population of thrushes visiting southern Italy is fairly homogeneous in size. The averages of the wing length, third primary length and tarsus length recorded for birds captured during the study are consistent with values obtained in the period from January to March in the Campania region in the years 2013-2016 (wing length $118.7 \mathrm{~mm}$, $S D$ 2.29, $N=150$; third primary $89.0 \mathrm{~mm}, S D 2.19, N=150$ and tarsus $32.5 \mathrm{~mm}$, $S D$ 0.57, $N=140$ ) (Scebba and Oliveri Del Castillo 2017) and in the Lazio region in the years 2012-2014 (wing length $118.8 \mathrm{~mm}, S D 2.67, N=341$; third primary $88.9 \mathrm{~mm}$, $S D$ 2.34, $N=340$ and tarsus $32.5 \mathrm{~mm}, S D$ 0.88, $N=335$ ) (Scebba et al. 2014), as well as for birds ringed in autumn in the Volturno Plain in Campania in the years 2003-2005 (118.5 mm, $S D$ 2.48, $N=1,340 ; 88.8 \mathrm{~mm}, S D 2.27, N=1,331$ and $32.3 \mathrm{~mm}$, $S D 0.97, N=1,333$ ) (Scebba 2006). It is therefore possible that these capture sites are located on the same migratory flow through central and southern Italy (Busse and Maksalon 1986).

The data collected in Calabria in the two provinces of Crotone and Reggio Calabria during the three-year study confirmed what was found in studies carried out in other regions of central and southern Italy: that the northward migration of Song Thrush can be identified in March, with early movements in February. As no migratory activity was detected before the second decade of February, the dates of the hunting season in southern Italy could be reconsidered. However, further study is needed to assess more accurately the movements of the species within and from its wintering area and the decade in which the first migratory movements take place.

\section{ACKNOWLEDGEMENTS}

Funding for this research was provided by the Federazione Italiana della Caccia (FidC) - Regione Calabria. We are also grateful to the late Dr Gennaro Giuffré (Consigliere Nazionale e Presidente FidC Regione Calabria) for having supported this research.

\section{REFERENCES}

Andreotti A., Bendini L., Piacentini D., Spina F. 1999. The role of Italy within the Song Thrush (Turdus philomelos) migratory system analyzed on the basis of ringing-recovery data. Vogelwarte 29: 33-44.

Andreotti A., Pirrello S., Tomasini S., Merli F. 2010. I Tordi in Italia. Biologia e conservazione delle specie del genere Turdus. Tipolitografia CSR, Rome. (in Italian)

Andreotti A., Serra L., Spina F. (eds.) 2004. Relazione tecnico-scientifica sull'individuazione delle decadi da riferire all'Italia nel documento "Key concepts of Article 7 (4) of Directive 79/409/EEC". Ist. Naz. Fauna Selvatica, pp. 1-50. (in Italian)

Bairlein F., Gwinner E. 1994. Nutritional mechanisms and temporal control of migratory energy accumulation in birds. Annual Review of Nutrition 14: 187-215. 
Berthold P. 2000. Vogelzug. Eine aktuelle Gesamtübersicht. Wissenschaftliche Buchgesellschaft, Darmstadt.

Berthold P., Friedrich W. 1979. Die Federlänge: Ein neues nützliches Flügelmass. Vogelwarte 30: 11-21.

Blem C. R. 1990. Avian energy storage. In: Power, D. M.(ed.), Current omithology. Plenum Press, New York, 7, pp. 59-113.

Busse P., Maksalon L. 1986. Migration pattern of European populations of Song Thrush. Ring 27, 1-2: 3-30.

Kaiser A. 1993. A new multi-category classification of subcutaneous fat deposits of Songbirds. Journal of Field Ornithology 64: 246-255.

Karr J.R. 1979. On the use of mist nets in the study of bird communities. Inland Bird Banding 51: $1-10$.

Karr J.R. 1981. Surveying birds with mist nets. In: Ralph C.J. and Scott J.M. (eds.), Estimating the numbers of terrestrial birds. Studies in Avian Biology 6: 62-67.

La Gioia G., Scebba S. 2009. Atlante delle migrazioni in Puglia. Edizioni Publigrafic, Trepuzzi (Le). (in Italian)

Licheri D., Spina F. 2002. Biodiversita dell'avifauna italiana: variabilita morfologica nei Passeriformi (Parte II: Alaudidae - Sylviidae). Biologia e Conservazione della Fauna 112: 1-208. (in Italian with English Summary)

Macchio S., Messineo A., Licheri D., Spina F. 1999. Atlante della distribuzione geografica e stagionale degli uccelli inanellati in Italia negli anni 1980-1994. Biologia e Conservazione della Fauna 103: 1-276. (in Italian with English Summary)

Roux D., Boutin J.M. 2003. Phénologie de la migration prénuptiale de la Grive musicienne, de la Grive mauvis et du Merle noir. Alauda 71: 447-458.

Scebba S. 2006. Tordo bottaccio Turdus philomelos: studio della migrazione autunnale in Campania. Uccelli d'Italia 31: 26-49. (in Italian with English Summary)

Scebba S., La Gioia M., Sorrenti M. 2015. Indagine sulla data d'inizio della migrazione prenuziale del Tordo bottaccio Turdus philomelos in Puglia. Uccelli d'Italia 40: 5-15. (in Italian with English Summary)

Scebba S., Moschetti G., Cortone P., Di Giorgio A. 1993. Check-list degli uccelli della Calabria aggiornata a gennaio 1993. Sitta 6: 33-45. (in Italian with English Summary)

Scebba S., Oliveri Del Castillo M. 2017. Timing of Song Thrush Turdus philomelos on pre-nuptial migration in southern Italy. Ornis Hungarica 25 (1): 109-119. DOI: 10.1515/orhu-2017-0008

Scebba S., Soprano M., Sorrenti M. 2014. Timing of the spring migration of the Song Thrush Turdus philomelos through southern Italy. Ring 36: 23-31. DOI: 10.2478/ring-2014-0002

Spina F., Serra L. (eds.) 2003. An update of periods of pre-nuptial migration and reproduction for ANNEX II species in Italy. Ist. Naz. Fauna Selvatica, pp. 1-174.

Spina F., Volponi S. 2008. Atlante della Migrazione degli Uccelli in Italia. 2. Passeriformi. Ministero dell'Ambiente e della Tutela del Territorio e del Mare, Istituto Superiore per la Protezione e la Ricerca Ambientale (ISPRA). Tipogr. SCR-Roma. (in Italian with English Summary)

Svensson L. 1992. Identification guide to European passerines. Naturhistoriska Riksmuseet, Stockholm. 